\title{
Véronique Magri-Mourgues, Le Voyage à pas comptés. Pour une poétique du voyage au XIX siècle
}

\section{Nicolas Courtinat}

\section{OpenEdition}

\section{Journals}

\section{Édition électronique}

URL : http://journals.openedition.org/studifrancesi/6667

DOI : $10.4000 /$ studifrancesi.6667

ISSN : 2421-5856

\section{Éditeur}

Rosenberg \& Sellier

\section{Édition imprimée}

Date de publication : 1 septembre 2010

Pagination : 376

ISSN : 0039-2944

\section{Référence électronique}

Nicolas Courtinat, « Véronique Magri-Mourgues, Le Voyage à pas comptés. Pour une poétique du voyage au xIx siècle », Studi Francesi [En ligne], 161 (LIV | II) | 2010, mis en ligne le 30 novembre 2015, consulté le 09 janvier 2021. URL : http://journals.openedition.org/studifrancesi/6667 ; DOI : https://doi.org/ $10.4000 /$ studifrancesi.6667

Ce document a été généré automatiquement le 9 janvier 2021.

\section{(c) $($ ) $(9)$}

Studi Francesi è distribuita con Licenza Creative Commons Attribuzione - Non commerciale - Non opere derivate 4.0 Internazionale. 


\title{
Véronique Magri-Mourgues, Le Voyage à pas comptés. Pour une poétique du voyage au XIX siècle
}

\author{
Nicolas Courtinat
}

\section{RÉFÉRENCE}

VÉRONIQUE MAGRI MOURGUES, Le Voyage à pas comptés. Pour une poétique du voyage au XIX siècle, Paris, Champion, «Lettres numériques», 2009, pp. 184.

1 Issu d'une thèse d'habilitation à diriger les recherches en langue et stylistique françaises, l'ouvrage de Véronique Magri-Mourgues se présente comme une analyse linguistique et «textométrique» du récit de voyage au XIX ${ }^{e}$ siècle. L'auteur a mené ses recherches dans un laboratoire CNRS, «Bases, corpus et langage», installé à l'Université Sophia-Antipolis de Nice. Son objectif est de définir une poétique, voire une «grammaire» du récit de voyage, à partir de l'analyse statistique de données textuelles, effectuée grâce au logiciel Hyperbase ( $c f$. p. 20). Le présent ouvrage s'adresse donc en priorité aux spécialistes de linguistique et de stylistique, initiés au vocabulaire propre à ces sciences («corpus lemmatisé», «tissage trans-phrastique», «collations de lexèmes», «bivocalité»...), et à ceux qu'intéressent les études quantitatives. La bibliographie de fin de volume ne mentionne d'ailleurs aucun ouvrage critique spécifiquement consacré à tel ou tel «écrivain-voyageur» du xix siècle: il s'agit d'ouvrages et d'articles traitant de «fictionnalité» (sic), de statistique textuelle, de linguistique, de stylistique... V. MagriMourgues s'inscrit dans le sillage de Pierre Guiraud et d'Étienne Brunet.

2 Les premières pages du livre exposent la méthode et définissent le corpus, qui embrasse presque tout le siècle, de Chateaubriand (Itinéraire de Paris à Jérusalem) à Loti (Japoneries d'automne, 1889), en passant par des noms très connus (Stendhal, Lamartine, Hugo, Sand, Nerval, Gautier, Flaubert...). V. Magri-Mourgues a pris le parti original de faire travailler l'ordinateur non sur un, mais sur deux textes d'un même auteur: le récit de 
voyage de tel ou tel écrivain est ainsi confronté, linguistiquement parlant, à un autre de ses textes, choisi pour son caractère narratif (par exemple, Un Hiver à Majorque et La Petite Fadette), l'idée étant de dégager, par comparaison, les spécificités du récit de voyage. Les principes d'écriture de ce type d'œuvre sont définis méthodiquement, chacun des chapitres se focalisant ensuite sur un auteur particulier, examiné à chaque fois «de plus près», comme le dit l'auteur lui-même.

Munie de son ordinateur, chiffres, pourcentages et graphiques à l'appui, V. MagriMourgues parvient à des conclusions éclairantes. Le récit de voyage au xix siècle lui apparaît d'abord comme un "genre substantif» (p. 168): les noms communs y abondent, preuve s'il en est que le genre viatique s'ancre dans un univers spatial concret (p. 64 s.). L'auteur saisit cette occasion pour analyser de près les stratégies descriptives d'un Hugo qui, dans une œuvre comme Le Rhin, tend au panoptique, à l'exhaustivité (mais avait-on vraiment besoin ici de la textométrie?). «L'orientation lyrique» est la deuxième caractéristique fondamentale du genre: en effet le «je» du récit de voyage, central, comme le rappelle après bien d'autres V. Magri-Mourgues, ne se réfère pas seulement au cas isolé de l'écrivain-voyageur; à maintes reprises, ce «je concret» vise à l'exemplarité, «se dilue dans le nous ou le on»: «[le je] se dissout dans l'intemporalité du présent», ajoute l'auteur, «pour laisser place à l'expression d'une voix qui se fait l'écho d'une expérience universelle» (p.122-123). L'analyse informatique invite aussi à d'autres constats, comme l'importance des périodes oratoires chez Lamartine (p. 130), qui contraste avec la relative pauvreté de son vocabulaire, la variété et la richesse lexicales d'un Chateaubriand, visibles dans l'abondance des «hapax» (p.133 s.), ou encore les différents emplois de l'interjection «ô» chez Nerval, qui montrent à quel point son récit de voyage joue sur les ruptures de ton, passant du lyrisme au burlesque (p. 92 s.).

4 Dernière caractéristique du récit de voyage, certainement la plus importante, et qui intéressera aussi les «littéraires»: la «dynamique performative», que V. MagriMourgues met en lumière à partir d'une étude des démonstratifs. Dans ces récits en effet, le "geste descriptif» n'a pas pour seule fonction de désigner, de rapporter. C'est un geste éminemment créateur: «un glissement» très net s'opère "du constatif au performatif» (p. 156), comme le montre l'ancienne figure rhétorique de l'hypotypose (ibid.). Il s'agit bien pour l'écrivain de «créer un monde» (p. 157 s.). Il est dommage, de ce point de vue, que les analyses sur la métaphore n'aient pu être davantage développées (p. 159). Apparemment les logiciels ne sont pas assez performants encore pour les «traiter» avec la pertinence nécessaire (ibid.).

On l'aura compris, l'ouvrage de V. Magri-Mourgues ne trouvera aucune grâce auprès de ceux que révulsent les études quantitatives. Que reste-t-il de nos augustes prosateurs, Chateaubriand, Lamartine, Hugo, Loti, une fois leur récit passé à la moulinette de la textométrie? Le récit de voyage au XIx ${ }^{\mathrm{e}}$ siècle n'est-il qu'agencement de faits de langue? Où sont exactement la beauté de ces textes, les valeurs qu'ils véhiculent? Que nous disent-ils sur le domaine humain? Les linguistes et stylisticiens auront bien entendu un tout autre regard sur ce livre de qualité, impeccablement présenté et mené avec la plus grande rigueur scientifique. Ils apprécieront en particulier l'heureux va-et-vient entre les mises au point théoriques sur des notions grammaticales importantes (qui aideront notamment les étudiants) et de très fines analyses de détail. 